\title{
SURGICAL TREATMENT OF ULCERATIVE COLITIS
}

\author{
Ivanov K., V. Ignatov, N. Kolev, A. Tonev \\ Department of General and Operative Surgery, University Hospital "St. Marina" - Varna
}

\author{
Reviewed by: Prof. I. Kotsev
}

\begin{abstract}
The ulcerative colitis has a frequency of 80 to 120 / 100000 per year in some regions, and there are founded 15 new cases up on 100000 people in Europe every year. Despite of success in conservative therapy, a big group of patients undergo surgical treatment. Absolute indications for surgery are the complications of ulcerative colitis (UC). General indications for surgical treatment are the failure and intractability of conservative therapy, bleeding, acute colitis, toxic mega colon, perforation, obstruction, dysphasia of intestinal mucosa, or carcinoma in the cases with more than 10 years with UC. The advancing to SMOF is poor prognostic factor, and the success of surgical treatment is defined by exact preoperative preparation. A problem is the need of resection of big bowel segment, the difficult choice for operative method including insurance of continence, the need of undergoing multiple-staged operations, and prŭcising the surgical tactics in cases of emergency. The quality of life in patients with $\mathrm{UC}$ is increasing after colectomy. The prolonged postoperative results depend from success of the treatment of systematic manifestation from the disease, as well as the way of life of the patients.
\end{abstract}

Key words: ulcerative colitis, surgical treatment

\section{INTRODUCTION}

The ulcerative colitis is first time described in 1859 , by Samuel Wilks in Guy's hospital, London. There are some regions with frequency of 80 to $120 / 100000$ per year. It is a diffuse inflammatory disease of the colorectal mucosa, which clinically is manifested with diary, abdominal pain, febris, weight-loss, and rectoraghia. The diagnosis is based up on data from clinical, endoscopical, radiological and morphological findings.

\section{Acute Colitis}

Patients with clinical evidence of actual or impending perforation should undergo urgent surgery. Severe acute colitis affects between 5 to 15 percent of patients with ulcerative colitis.

The diagnosis of severe colitis is based on the criteria of Truelove and Witts (1) and is defined as colitis with more than six bloody stools per day, fever (temperature, $>37.5^{\circ} \mathrm{C}$ ), tachycardia (heart rate, $>90$ beats per minute), anemia (hemoglobin, $<75$ percent of normal), and elevated sedimentation rate (ESR, $>30 \mathrm{~mm}$ per hour). When the colonic distention of the transverse colon exceeds $6 \mathrm{~cm}$, the diagnosis becomes toxic megacolon (2). Surgery is required in 20 to 30 percent of patients with toxic colitis (5). Perforation in patients with toxic colitis has a high mortality rate, which ranges from 27 to 57 percent regardless of whether the perforation is contained or free.

\section{Address for correspondence:}

Kr.Ivanov, Varna, $1 \mathrm{Hr}$. Smirnenski str,

University Hospital "St. Marina"

e-mail: teraton@abv.bg, kivanov@gisurgery.bg
Patients with toxic colitis receiving surgical intervention before perforation have a significantly better outcome than those operated on after perforation.

Patients whose condition worsens on medical therapy or who fail to make significant improvement after a period of 48 to 96 hours of appropriate medical therapy should be considered for surgery (3). The need for and timing of surgery in patients whose condition seems to "plateau" after a period of initial improvement often is difficult to judge.

However, patients with more than eight stools per day or three to eight stools and a C-reactive protein $>45 \mathrm{mg} / \mathrm{ml}$ after three days of therapy have an 85 percent chance of requiring colectomy during the same hospitalization, regardless of whether corticosteroid or cyclosporine treatment is used (4). Most series define a period of 48 to 96 hours after which surgery is indicated if the patient fails to improve, although evidence specifying the most appropriate time period for a trial of medical therapy, especially with "second-line" agents, is lacking. Surgery is indicated in ulcerative colitis when medical therapy is ineffective. Intractability is one of the most common surgical indications for ulcerative colitis. Medical therapy can fail for several reasons. Symptoms may be insufficiently controlled despite an intensive medical regimen and the patient is unable to achieve an acceptable quality of life (6-11).

Alternatively, the response to treatment may be adequate, but the risks of chronic medical therapy (especially long-term corticosteroids) may be excessive. Patients also may be unable to tolerate the deleterious side effects of medical therapy. Patients who are noncompliant with treatment regimens might be candidates for surgical manage- 
ment. The postoperative quality of life for patients with ulcerative colitis is improved after colectomy (12-16).

\section{Cancer Risk}

Patients with long-standing ulcerative colitis should undergo endoscopic surveillance. Although it is clear that patients with longstanding ulcerative colitis have an increased risk of colorectal cancer, its magnitude has been difficult to estimate. A recent meta-analysis estimated the risk of colorectal cancer for a patient with colitis to be 2 percent at 10 years, 8 percent at 20 years, and 18 percent after 30 years of disease (15-18).

Surveillance colonoscopy has been recommended in these patients despite a lack of clear evidence that shows surveillance prolongs survival in patients with ulcerative colitis (19).

Carcinomas tend to be detected at an earlier stage in persons who are undergoing surveillance colonoscopy, and these patients have a better prognosis. Surveillance colonoscopies should be ideally performed when the disease is in remission to minimize confusion regarding neoplasia (20).

2. Patients with ulcerative colitis who develop a stricture, especially with long-standing disease, should undergo resection. Strictures develop in 5 to 10 percent of patients with ulcerative colitis (20-26).

Although the majority of strictures are benign, as many as 25 percent will be malignant, and malignant strictures account for up to 30 percent of cancers occurring in ulcerative colitis patients (24-29).

Strictures that arise on a background of long-standing disease, originate proximal to the splenic flexure, or cause obstructive symptoms are more likely to be malignant (50). Endoscopic biopsy of strictures can reveal dysplasia or malignancy but may be unreliable because of sampling error and the more infiltrating nature of colitis-associated malignancies (28).

\section{Surgical options \\ Emergency}

The most appropriate operative procedure for emergency surgery in ulcerative colitis is total or subtotal abdominal colectomy with end ileostomy. The surgical alternatives in the acute setting are designed to restore patient health with the greatest reliability and minimal risk while preserving reconstructive options after the patient has recovered (30).

Subtotal colectomy with end ileostomy and Hartmann's closure of the distal bowel or creation of a mucous fistula is a safe and effective approach (31).

This procedure removes the majority of the inflamed bowel with a comparatively straightforward operation and avoids pelvic dissection as well as an intestinal anastomosis (34) Compared with intraperitoneal closure of the rectal stump, extrafascial placement of a closed rectosigmoid stump may be associated with fewer pelvic septic complications and facilitates subsequent pelvic dissection (32).

Transanal drainage of the distal stump may further decrease the risk of pelvic sepsis (35).
The resected colon specimen should be histopathologically examined for confirmation of ulcerative colitis or Crohn's disease because the likelihood of an altered diagnosis is appreciable after colectomy (36-39).

In patients with ulcerative colitis, a completion proctectomy and ileal pouch-anal anastomosis (IPAA) often can be safely performed at a later date to remove the remaining disease and restore intestinal continuity (37).

If the diagnosis is Crohn's disease and the rectum is reasonably compliant and distensible, consideration may be given to an ileorectal anastomosis (40).

\section{Elective Surgery}

1. Total proctocolectomy with ileostomy is an appropriate surgical alternative for patients with ulcerative colitis. Proctocolectomy with ileostomy has been the conventional operative approach for patients with ulcerative colitis and may be considered a benchmark procedure to which all other operations are compared (29-34). It has been established as a safe, curative operation that permits most patients to live a full, active lifestyle $(21,24,33)$.

Although restorative proctocolectomy with IPAA has become increasingly popular during the past two decades, proctocolectomy with ileostomy can still be considered the first-line procedure for patients who choose not to undergo a restorativ proctocolectomy and for those at significant risk for pouch failure, such as patients with impaired anal sphincter muscles, previous anoperineal disease, or limited physiologic reserve secondary to comorbid conditions (41-43).

The operation, however, does have recognized complications.

Although stoma-associated problems, such as intestinal obstruction, the cancer-related complications, intestinal fistula, persistent pain, unhealed perineal wound, sexual and bladder dysfunction, and infertility are common to any abdominal/pelvic procedure also have been recognized (44).

In one recent study of 44 patients, the long-term complication rate of proctocolectomy with permanent ileostomy was significantly lower than restorative proctocolectomy ( 26 vs. 52 percent) (45).

2. Total proctocolectomy with ileal pouch-anal anastomosis is an appropriate operation for most patients with ulcerative colitis. Total proctocolectomy with IPAA has become the most commonly performed procedure for patients with ulcerative colitis requiring elective surgery $(5,16)$.

The operation is relatively safe and durable, associated with an acceptable morbidity rate (19 to 27 percent an extremely low mortality rate (0.2-0.4 percent), and a quality of life that approaches that of the normal population. The complications of the procedure include those of any major abdominal operation: risks arising from the pelvic dissection, such as infertility or sexual dysfunction, and pouchspecific complications (45). 
a) Total proctocolectomy with IPAA may be appropriately offered to selected ulcerative colitis patients with concomitant colorectal cancer. Studies examining the use of IPAA in patients with invasive cancers of the colon or upper rectum without distant metastases have yielded somewhat conflicting findings. In several series, ulcerative colitis patients with a concomitant carcinoma had a rate of postoperative complications and functional results comparable to colitis patients without cancer; metastatic disease developed in a small number of patients. In contrast, a separate study revealed that nearly 20 percent of ulcerative colitis patients with cancer who underwent an IPAA subsequently died of metastatic disease $(15,22,45)$.

A more conservative management approach has been advocated by some who recommend an abdominal colectomy with ileostomy followed by a restorative proctectomy after an observation period of at least 12 months to better assure that no recurrent disease develops. Metastatic disease is generally considered a contraindication to IPAA $(23,35)$.

These patients should usually be managed with segmental colectomy or abdominal colectomy with anastomosis to facilitate early discharge and allow them to spend the rest of their lives relatively free of complications. Another group of patients who may not be eligible for IPAA are those with invasive carcinomas of the mid or low rectum, because basic principles of cancer surgery may be compromised $(29,44)$.

Adjuvant radiotherapy, if indicated, should be performed preoperatively whenever possible, because postoperative radiotherapy is associated with a high incidence of pouch loss secondary to radiation enteritis and poor pouch function. Ulcerative colitis patients with cecal cancers represent another unique subgroup of patients $(28,48)$.

If a long segment of adjacent distal ileum with its mesenteric vessels must be sacrificed, difficulties with positioning of the reservoir into the pelvis may ensue, and an ileostomy may be necessary if a tension-free anastomosis cannot be attained $(12,50)$.

b) Total proctocolectomy with IPAA may be appropriately offered to selected elderly patients with ulcerative colitis. Many groups have demonstrated that IPAA in the elderly patient is safe and feasible. Chronologic age should not itself be used as an exclusion criterion. However, careful consideration should be given to other comorbidities, as well as the patient's mental status and anal sphincter function $(16,43)$.

c) Mucosectomy and double-stapled procedures are both appropriate techniques in most circumstances. The potential advantages of the double-stapled approach include enhanced technical ease because it avoids mucosectomy and the perineal phase of the operation, there is less tension on the anastomotic suture line, and possibly improved functional results (15).

Sphincter injury is minimized and the anal transition zone with its abundant supply of sensory nerve endings is preserved. Three prospective, randomized trials have demonstrated no significant difference in perioperative complications or functional results for patients in whom a mucosectomy was performed vs. those patients in whom the proximal anal canal mucosa was preserved $(1,41,45)$.

d) Pouch configuration may be chosen based on individual preference. Although the initial ileal reservoir created by Parks in the late 1970s was a triple-loop S-pouch, other pouch configurations have been described in an attempt to reduce pouch complications and improve functional outcome. These include the double-loop J-pouch, the lateral isoperistaltic H-pouch, and the quadruple-loop W-pouch (33).

S-pouches were initially plagued with evacuation problems associated with a long $(5 \mathrm{~cm})$ exit conduit, frequently requiring pouch catheterization. With shortening of the exit conduit to $2 \mathrm{~cm}$, mandatory catheterization has been substantially reduced. The long outlet tract formed in the H-pouch also was associated with pouch distention, stasis, and pouchitis (25).

The W-pouch has been advocated because of a greater capacity. However, two randomized trials comparing the J-pouch and $\mathrm{W}$-pouch did not substantiate an improvement in functional outcomes. An S-pouch can provide additional length $(2-4 \mathrm{~cm})$ compared with the J-pouch and may help minimize anastomotic (17).

e) A diverting loop ileostomy may be reasonably omitted in some patients. Retrospective and prospective trials suggest that one-stage restorative proctocolectomy can be safely performed in selected patients by experienced surgeons. The one-stage procedure is associated with a more challenging early recovery, as well as a slightly increased rate of anastomotic disruption and pelvic sepsis (15-21).

Although some disagree, these complications should usually be managed with fecal diversion because of concerns about compromised functional outcome and resultant pouch loss. Despite aggressive nonoperative and operative measures, the estimated cumulative three-, fiveand ten-year rate of pouch failure in all patients with septic complications is 20,31 , and 39 percent, respectively (36). 
This highlights the need for great caution when considering pelvic pouch surgery without temporary diversion. Single-stage IPAA avoids the risks of ileostomy closure, which include anastomotic leaks from the closure site and an increased incidence of postoperative small-bowel obstruction that often mandates hospitalization or laparotomy (16).

In general, selective omission of the ileostomy may be considered safe when the anastomosis appears intact, is under no tension, the procedure is not complicated by excessive bleeding or other technical difficulties, and the patient is not on high doses of corticosteroids before surgery (44).

f) Routine surveillance of ileal pouches for dysplasia in the ileal mucosa is not warranted A decrease in villous height and increase in concentration of crypts have been observed in most ileal pouches. These metaplastic changes of the ileal mucosa to a colonic type mucosa are considered adaptations to the reservoir function of the pouch (50).

This transformation also may be driven by the chronic inflammation frequently observed in these pouches. However, dysplastic and neoplastic transformation within the pouch seems to be extremely rare.

g) Pouchitis is common after IPAA and readily managed with antibiotics in most circumstances. The most frequent long-term complication after IPAA for ulcerative colitis is a nonspecific inflammation of the ileal pouch known as pouchitis. The presence of extraintestinal manifestations of ulcerative colitis before colectomy, especially primary sclerosing cholangitis, has been associated with an increased incidence of pouchitis (31-34).

It is unclear whether the presence of backwash ileitis or extent of disease predict the likelihood of ultimately developing pouchitis. The etiology of this nonspecific inflammation is unclear but may be the result of an overgrowth of anaerobic bacteria. Presenting symptoms usually include abdominal cramps, fever, pelvic pain, and an increase in stool frequency (44).

Clinical diagnosis may require confirmation by endoscopy and pouch mucosal biopsy, because clinical symptoms alone can be misleading. Patients suffering with chronic pouchitis should be assessed for a diagnosis of Crohn's disease. Uncommonly, an ileostomy with or without pouch excision is required for severe refractory pouchitis (42).

3. Continent ileostomy is an alternative surgical option for patients with ulcerative colitis The present role of the continent ileostomy is primarily confined to patients with poor sphincter function, a failed IPAA, or those who are dissatisfied with a conventional Brooke ileostomy $(4,13,17)$.
This reduced role is the result of the success of the IPAA and the high rate of early and late complications associated with the continent ileostomy. Early complications are seen in approximately onequarter of patients, most commonly sepsis (secondary to suture line leaks, fistulas, and stomal necrosis) and obstruction.

Late complications occur in up to 50 percent of patients and include incontinence and obstruction secondary to disruption or dysfunction of the valve; valve revision is required in up to 60 percent of patients. Although valve prolapse has been reduced with stapling techniques, the overall pouch failure rate has not decreased (5).

The cumulative success rate of the continent ileostomy in a recent study was 71 percent at 29 years. The failure rate is greater after secondary construction after a failed IPAA (46 percent) than after primary construction (23 percent). For the two-thirds of patients with a functional continent ileostomy, the reported quality of life is similar to that described for patients with IPAA (21).

4. Total abdominal colectomy with ileoproctostomy is an acceptable surgical approach in a highly selected group of patients with ulcerative colitis. Because the performance of a total abdominal colectomy with ileoproctostomy requires a relatively normal rectum to create a safe anastomosis, severe rectal inflammation or a marked decrease in rectal distensibility are contraindications to the procedure. Severe anoperineal disease, although unusual in ulcerative colitis, also precludes an ileorectal anastomosis (33).

Whereas the benefits of total abdominal colectomy with ileoproctostomy are its relative simplicity and predictability compared with IPAA, the disadvantages are related to the long-term durability of the procedure. Studies demonstrate a 12 to 50 percent failure rate with follow-up of more than six years. In addition, the theoretical risk of developing cancer in the remaining rectum should be considered when counseling the patient and other options discussed (35).

Although the incidence of developing cancer seems to be low (0-6 percent with long-term followup), patients undergoing total abdominal colectomy with ileorectal anastomosis must be willing to undergo annual endoscopic screening (49).

\section{LITERATURE}

1. Truelove SC, Witts LF. Cortisone in ulcerative colitis: final report on a therapeutic trial. $B M J 1955$; 2:1041-8.

2. Hanauer SB. Drug therapy: inflammatory bowel disease. N Engl J Med 1996;334:841-8.

3. Jones JH, Chapman M. Definition of megacolon in colitis. Gut 1969;10:562-4.

4. Katz JA. Medical and surgical management of severe colitis. Semin Gastrointest Dis 2000;11:18-32.

5. Present DH. Toxic megacolon. Med Clin North Am 1993;77:1129-48. 
6. Greenstein AJ, Barth JA, Sachar DB, Aufses AH Jr. Free colonic perforation without dilatation in ulcerative colitis. Am J Surg 1986;152:272-5.

7. Heppell J, Farouk E, Dube S, Peloquin A, Morgan S, Bernard D. Toxic megacolon. An analysis of 70 cases. Dis Colon Rectum 1986;29:789-92.

8. Greenstein AJ, Sachar DB, Gibas A, et al. Outcome of toxic dilatation in ulcerative and Crohn's colitis. J Clin Gastroenterol 1985;7:137-43.

9. Berg DF, Bahadusingh AM, Kaminski DL, Longo WE. Acute surgical emergencies in inflammatory bowel disease. Am J Surg 2002;184:45-51.

10. St Peter SD, Abbas MA, Kelly KA. The spectrum of pneumatosis intestinalis. Arch Surg 2003; 138:68-75.

11. Roy M. Inflammatory bowel disease. Surg Clin North Am 1997;77:1419-36.

12. Caprilli R, Latella G, Vernia P, Frieri G. Multiple organ dysfunction in ulcerative colitis. $A m \mathrm{~J}$ Gastroenterol 2000;95:1258-62.

13. Lichtiger S, Present DH, Kornbluth A, et al. Cyclosporine in severe ulcerative colitis refractory to steroid therapy. N Engl J Med 1994;330:1841-5.

14. D'Haens G, Lemmens L, Geboes K, et al. Intravenous cyclosporine versus intravenous corticosteroids as single therapy for severe attacks of ulcerative colitis. Gastroenterology 2001;120:1323-9.

15. Shibolet O, Regushevskaya E, Brezis M, Soares-Weiser K. Cyclosporine A for induction of remission in severe ulcerative colitis. Cochrane Database of Systematic Reviews. 1, 2005.

16. Travis SP, Farrant JM, Ricketts C, et al. Predicting outcome in severe ulcerative colitis. Gut 1996;38:905-10.

17. Latella G, Viscido A, Frieri G, et al. GI distension in severe ulcerative colitis. Am J Gastroenterol 2002;97: 1169-75.

18. Hyman NH, Cataldo P, Osler T. Urgent subtotal colectomy for severe inflammatory bowel disease. Dis Colon Rectum 2005;48:70-3.

19. McLeod RS, Churchill DN, Lock AM, Vanderburgh S, Cohen Z. Quality of life of patients with ulcerative colitis preoperatively and postoperatively. Gastroenterology 1991;101:1307-13.

20. McLeod RS, Baxter NN. Quality of life of patients with inflammatory bowel disease after surgery. World J Surg 1998;22:375-81.

21. Sagar PM, Lewis W, Holdsworth PJ, Johnston D, Mitchell C, MacFie J. Quality of life after restorative proctocolectomy with a pelvic ileal reservoir compares favorably with that of patients with medically treated colitis. Dis Colon Rectum 1993;36:584-92.

22. Thirlby RC, Land JC, Fenster LF, Lonborg R. Effect of surgery on health-related quality of life in patients with inflammatory bowel disease: a prospective study. Arch Surg 1998;133:826-32.

23. Muir AJ, Edwards LJ, Sanders LL, et al. A prospective evaluation of health-related quality of life after ileal pouch anal anastomosis for ulcerative colitis. Am J Gastroenterol 2001;96:1480-5.

24. Berger M, Gribetz D, Korelitz BI. Growth retardation in children with ulcerative colitis: the effect of medical and surgical therapy. Pediatrics 1975;55:459-67.

25. Eaden JA, Abrams K, Mayberry JF. The risk of colorectal cancer in ulcerative colitis: a meta-analysis. Gut 2001;48:526-35.

26. Hata K, Watanabe T, Kazama S, et al. Earlier surveillance colonoscopy programme improves survival in patients with ulcerative colitis associated colorectal cancer: results of a 23-year surveillance programme in the Japanese population. Br J Cancer 2003;89:1232-6.

27. Mpofu C, Watson AJ, Rhodes JM. Strategies for detecting colon cancer and/or dysplasia in patients with inflammatory bowel disease. Cochrane Database of Systematic Reviews. 1, 2005.

28. Riddell RH. Screening strategies in gastrointestinal cancer. Scand J Gastroenterol Suppl 1990;175:177-84.

29. Winawer S, Fletcher R, Rex D, et al. Colorectal cancer screening and surveillance: clinical guidelines and rationale - update based on new evidence. Gastroenterology 2003;124:544-60.

30. Kornbluth A, Sachar DB. Practice Parameters Committee of the American College of Gastroenterology. Ulcerative colitis practice guidelines in adults (update): American College of Gastroenterology, Practice Parameters Committee. Am J Gastroenterol 2004;99: 1371-85.

31. Rubin CE, Haggitt RC, Burmer GC, et al. DNA aneuploidy in colonic biopsies predicts future development of dysplasia in ulcerative colitis. Gastroenterology 1992;103:1611-20.

32. Rutter MD, Saunders BP, Schofield G, Forbes A, Price AB, Talbot IC. Pancolonic indigo carmine dye spraying for the detection of dysplasia in ulcerative colitis. Gut 2004;53:256-60.

33. Sada M, Igarashi M, Yoshizawa S, et al. Dye spraying and magnifying endoscopy for dysplasia and cancer surveillance in ulcerative colitis. Dis Colon Rectum 2004;47:1816-23.

34. Jayaram H, Satsangi J, Chapman RW. Increased colorectal neoplasia in chronic ulcerative colitis complicated by primary sclerosing cholangitis: fact or fiction? Gut 2001;48:430-4.

35. Shapiro BD, Lashner BA. Cancer biology in ulcerative colitis and potential use in endoscopic surveillance. Gastrointest Endosc Clin N Am 1997;7:453-68.

36. Bernstein CN, Shanahan F, Weinstein WM. Are we telling patients the truth about surveillance colonoscopy in ulcerative colitis? Lancet 1994;343:71-4.

37. Ullman TA, Loftus EV, Kakar S, Burgart LJ, Sandborn WJ, Tremaine WJ. The fate of low grade dysplasia in ulcerative colitis. Am J Gastroenterol 2002;97:922-7.

38. Connell WR, Lennard-Jones JE, Williams CB, Talbot IC, Price AB, Wilkinson KH. Factors affecting the outcome of endoscopic surveillance for cancer in ulcerative colitis. Gastroenterology 1994;107:934-44.

39. Befrits R, Ljung T, Jaramillo E, Rubio C. Low-grade dysplasia in extensive, long-standing in- 
flammatory bowel disease: a follow-up study. Dis Colon Rectum 2002;45:615-20.

40. Dixon MF, Brown LJ, Gilmour HM, et al. Observer variation in the assessment of dysplasia in ulcerative colitis. Histopathology 1988;13:385-97.

41. Connell WR, Talbot IC, Harpaz N, et al. Clinicopathological characteristics of colorectal carcinoma complicating ulcerative colitis. Gut 1994;35:1419-23.

42. Eaden JA, Abrams K, Mayberry JF. The risk of colorectal cancer in ulcerative colitis: a meta-analysis. Gut 2001;48:526-35.

43. Odze RD, Goldblum J, Noffsinger A, Alsaigh $\mathrm{N}$, Rybicki LA, Fogt F. Interobserver variability in the diagnosis of ulcerative colitis-associated dysplasia by telepathology. Mod Pathol 2002;15:379-86.

44. Medlicott SA, Jewell LD, Price L, Fedorak RN, Sherbaniuk RW, Urbanski SJ. Conservative management of small adenomata in ulcerative colitis. Am J Gastroenterol 1997;92:2094-8.

45. Rubin PH, Friedman S, Harpaz N, et al. Colonoscopic polypectomy in chronic colitis: conservative management after endoscopic resection of dysplastic polyps. Gastroenterology 1999;117:1295-300.

46. Odze RD, Farraye FA, Hecht JL, Hornick JL. Long-term follow-up after polypectomy treatment for adenomalike dysplastic lesions in ulcerative colitis. Clin Gastroenterol Hepatol 2004;2:534-41.

47. Pinczowski D, Ekbom A, Baron J, Yuen J, Adami HO. Risk factors for colorectal cancer in patients with ulcerative colitis: a case-control study. Gastroenterology 1994;107:117-20.

48. Moody GA, Jayanthi V, Probert CS, Mac Kay H, Mayberry JF. Long-term therapy with sulfasalazine protects against colorectal cancer in ulcerative colitis: a retrospective study of colorectal cancer risk and compliance with treatment in Leicestershire. Eur J Gastroenterol Hepatol 1996;8:1179-83.

49. Eaden J, Abrams K, Ekbom A, Jackson E, Mayberry J. Colorectal cancer prevention in ulcerative colitis: a case-control study. Aliment Pharmacol Therap 2000; 14:145-53.

50. Gumaste V, Sachar DB, Greenstein AJ. Benign and malignant strictures in ulcerative colitis. Gut 1992;33: 938-41. 